\title{
Spinal alignment, mobility of the hip and thoracic spine and prevalence of low back pain in young elite cross- country skiers
}

\author{
Marie Alricsson ${ }^{1,2 * *}$, Glenn Björklund', Martin Cronholm³, Oscar Olsson ${ }^{3}$, Peter Viklund ${ }^{3}$, Ulla Svantesson ${ }^{1,4}$ \\ 'Swedish Winter Sport Research Centre, Department of Health Sciences, Mid Sweden University, Östersund, Sweden \\ 2Department of Sports Science, Linnaeus University, Kalmar, Sweden \\ ${ }^{3}$ Scandinavian College of Naprapathic Manual Medicine, Stockholm, Sweden \\ ${ }^{4}$ Sahlgrenska Academy, Institute of Neuroscience \& Physiotherapy, University of Gothenburg, Gothenburg, Sweden
}

This study investigated the association between spinal alignment, mobility of the hips and the thoracic spine and low back pain in adolescent cross-country skiers. Cohort of 51 elite cross-country skiers from a cross-country skiing high school in Sweden participated in the study. Sagittal spinal alignment, active range of motion in flexion, extension and rotation of the thoracic spine as well as passive and active extension of the hips were measured. The participants also completed a questionnaire regarding training, competition, skiing technique and occurrence of low back pain. A simple linear regression was calculated to predict pain score based on thoraco-lumbar relation, with a significant $(P<0.05)$ regression equation of $y=-0.069 x+2.280$ (standard error of esti- mate, 0.034). Participants with greater lordosis than kyphosis were more likely to suffer from low back pain than subjects without this offset. Thoracic mobility and passive or active hip extension showed no correlation with low back pain. Sagittal spinal alignment seems to be related with low back pain among young elite cross-country skiers. This study shows that range of motion of the thoracic spine and hips do not have an effect on the prevalence of low back pain in this population.

Keywords: Back problems, De Brunner kyphometer, Range of motion, Sport injury

\section{INTRODUCTION}

There are several studies focusing on biomechanics and performance in cross-country skiing (Holmberg et al., 2005; Lindinger et al., 2009) but very few have paid attention to biomechanics and pain. Although the injury rate among skiers is low, there is an increasing number of low back pain (LBP) among adolescent skiers (Bergstrøm et al., 2004). Studies including younger skiers have shown a high frequency of LBP, compared to age-matched control groups (Bahr et al., 2004; Bergstrøm et al., 2004). The type of technique used in skiing has been suspected to play a major role in the development of back pain in skiers, and most of those with a history of LBP reported diagonal skiing to be the most provocative (Alricsson and Werner, 2005; Eriksson et al., 1996; Renstrom and Johnson, 1989; Ristolainen et al., 2010). During diagonal skiing, hip extension is an important force producer; therefore, the ability to extend the hips becomes highly relevant. Furthermore, increased cycle rate along with a large peak leg force is key factor in achieving a rapid diagonal stride (Andersson et al., 2014).

Renstrom and Johnson (1989) believed that the repeated hyperextension of the lumbar spine seen in every hip extension was the potential cause of the pain noted in classical skiers. Eriksson et al. (1996) alleged that prolonged static contractions of the erector spinae muscle could be the cause of pain with the diagonal technique. Mahlamäki (1987) showed that increased tension in the hip flexor muscles and increased soreness of the erector spinae muscles were common among skiers with LBP. The increase in muscle tone of both these muscle groups could be the cause of in-
${ }^{*}$ Corresponding author: Marie Alricsson (iD http://orcid.org/0000-0001-6653-3414 Swedish Winter Sport Research Centre, Department of Health Sciences, Mid Sweden University, SE-83125 Östersund, Sweden Tel: +46-0-10-1428803, Fax: +46-63165626, E-mail: marie.alricsson@miun.se Received: November 20, 2015 / Accepted: January 14, 2016
This is an Open Access article distributed under the terms of the Creative Commons Attribution Non-Commercial License (http://creativecommons.org/licenses/by-nc/4.0/) which permits unrestricted non-commercial use, distribution, and reproduction in any medium, provided the original work is properly cited. 
creased lordosis of the lumbar spine. The one-sided poling in diagonal skiing also necessitates rotation of the torso, which is mostly done in the thoracic spine. Farfan et al. (1970) showed that repetitive torsional trauma may cause instability in the low back and that repeated rotation with the diagonal technique may result in LBP.

In double poling, a strategy to achieve a more effective double poling technique, skiers exhibit a higher hip angle velocity along with a smaller minimum hip angle (Holmberg et al., 2005). This repeated flexion and extension in the poling phase is also considered as being another potential cause of pain, in earlier research (Renstrom and Johnson, 1989).

The relation between back pain and altered biomechanics has been reported in several studies (Alricsson et al., 2003; Alricsson and Werner, 2004; Alricsson and Werner, 2006; Mellin, 1987; Mellin, 1990). Mellin (1990) found decreased mobility of the hips, reduced thoracic mobility and particularly, decreased thoracic extension in young females who suffered from LBP. There was also an increased lordosis among those females with back pain. Another study by Mellin (1987) found decreased mobility of the thoracic spine with rotation and lateral flexion especially decreased in a population of middle-aged men suffering from LBP. Several studies conducted by Alricsson et al. (2003) and Alricsson and Werner (2004) showed that dancing on a regular basis was beneficial for increasing mobility in the spine and in the lower extremities, something which in one of the studies led to increased performance in some functional tests in young cross-country skiers (Alricsson et al., 2003). In one of these studies, significant decrease in LBP was noted in the intervention group (Alricsson and Werner, 2004). In another study by Alricsson and Werner (2006), there was an increase in the relation between thoracic kyphosis and lumbar lordosis among young elite cross-country skiers over a 5-yr period. The skiers suffering from LBP at follow-up had a significantly increased thoracic-lumbar relation, compared to skiers without LBP (Alricsson and Werner, 2006).

The purpose of the present study was to investigate the association between spinal alignment, mobility of the hips and the thoracic spine and LBP in young elite cross-country skiers.

\section{MATERIALS AND METHODS}

\section{Participants}

Fifty-one cross-country skiers (30 males and 21 females) aged 16-19 yr, from a cross-country skiing high school in Sweden, participated in the study. There were no exclusion criteria. All skiers were well-trained young individuals at top international or national level of their age groups. As the present high school is a boarding school, the skiers came from different parts of Sweden.

An oral approval was obtained from the headmaster of the cross-country ski high school. Participation was voluntary, and all participants (or parents if the participants were under 18-yr-old) gave their informed written consent to participate in the study. Ethical approval was obtained from the Ethical Advisory Board in South East Sweden (Dnr EPK 214-2014).

\section{Questionnaire}

All participants answered a questionnaire about training- and competition status, presence and location of pain, preferred style of skiing, etc. A modified version of an earlier questionnaire published by Eriksson et al. (1996), tailored for cross-country skiers, was used in the present study. The questionnaire was test-retested for reliability by Alricsson and Werner (2005) and showed very good reliability $(r=1.0)$ with no systematic differences between test occasions.

The participants also answered complementary questions about the severity of pain and functional deficit due to back pain (Von Korff et al., 1992). LBP was defined as pain or discomfort somewhere between the twelfth rib and the lower gluteal fold. This localisation has been set by the European Guidelines (Airaksinen et al., 2006). The answers in the complementary questionnaire were used to form an individual pain score for every subject. Pain Score is a measurement of the severity and functional deficit due to back pain among the subjects. The Pain Score was based on three questions from a questionnaire by Von Korff et al. (1992) targeting present pain, worst pain and the impact of pain in everyday life, including skiing. Each question consisted of a numeric rating scale of 10 points. The sum of the questions was divided by three to get the Pain Score.

\section{Sagittal alignment of the thoracic and lumbar spine}

The first part of the test protocols aimed to obtain the participants' degrees of kyphosis and lordosis in upright standing position with DeBrunner's kyphometer (Protek AG, Bern, Switzerland). Each participant's degrees of kyphosis and lordosis were then added to get an individual thoraco-lumbar relation in degrees. The participant was instructed to be in a relaxed standing position (Fig. 1). Therapist 1 palpated each spinous process starting from $\mathrm{C} 7$ and continued downward to S2. The skin was marked with a pen between T2-T3, T11-T12, and S1-S2, and these marks were used as a point of reference throughout the fol- 


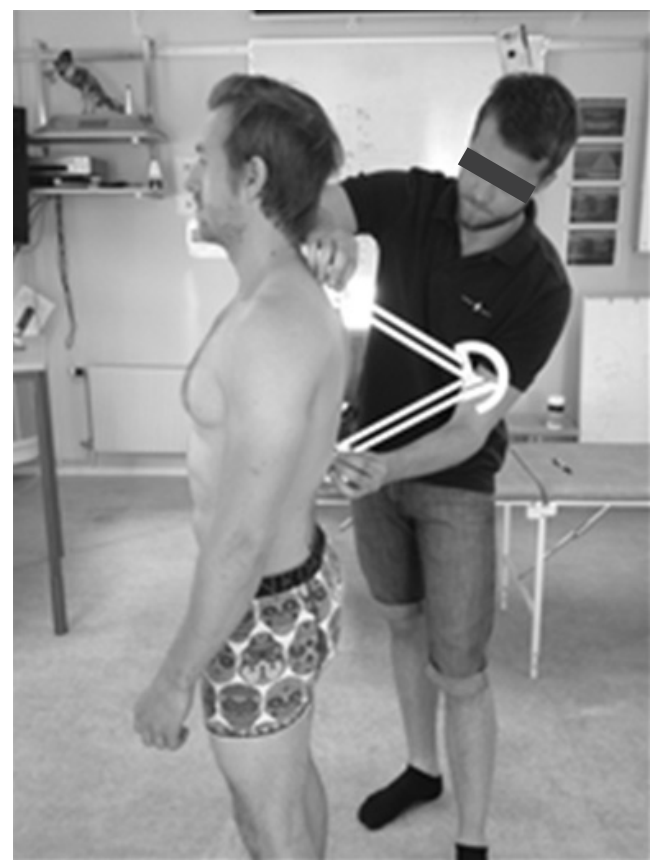

Fig. 1. Measuring sagittal alignment with a Debrunner kyphometer.

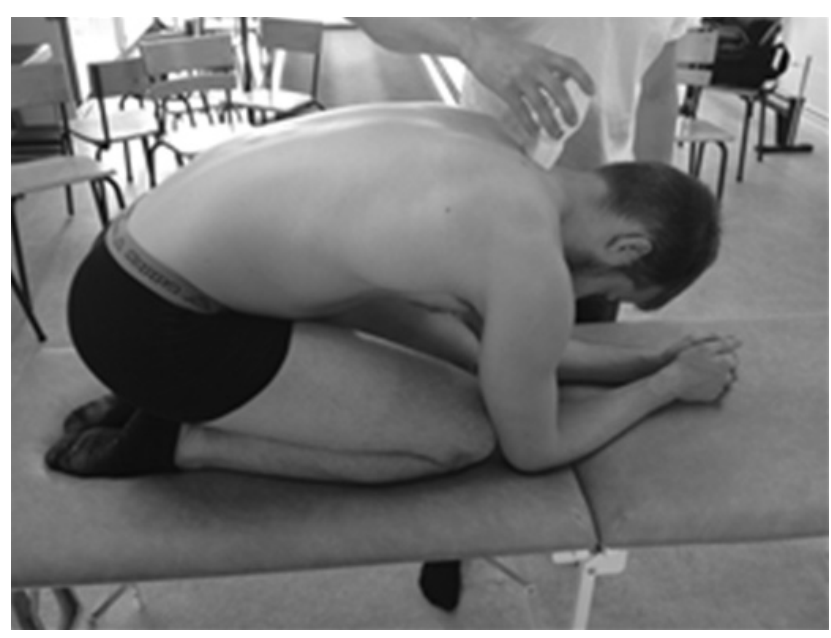

Fig. 2. Starting position for the lumbar locked thoracic rotation test.

lowing test. The level arms of the kyphometer were placed at the marks T2-T3 and T11-T12 to obtain the amount of kyphosis. The amount of lumbar lordosis was measured using the same method, with the kyphometer placed between the T11-T12 and S1-S2 marks. The next part of the test protocol aimed to obtain the participants' thoracic flexion and extension ability. The participants were instructed to bend their trunk forward and flex the thoracic spine as much as possible while keeping the knees fully extended. Extension of the spine was then tested by instructing the participant to lean backward while keeping the neck in a neu-

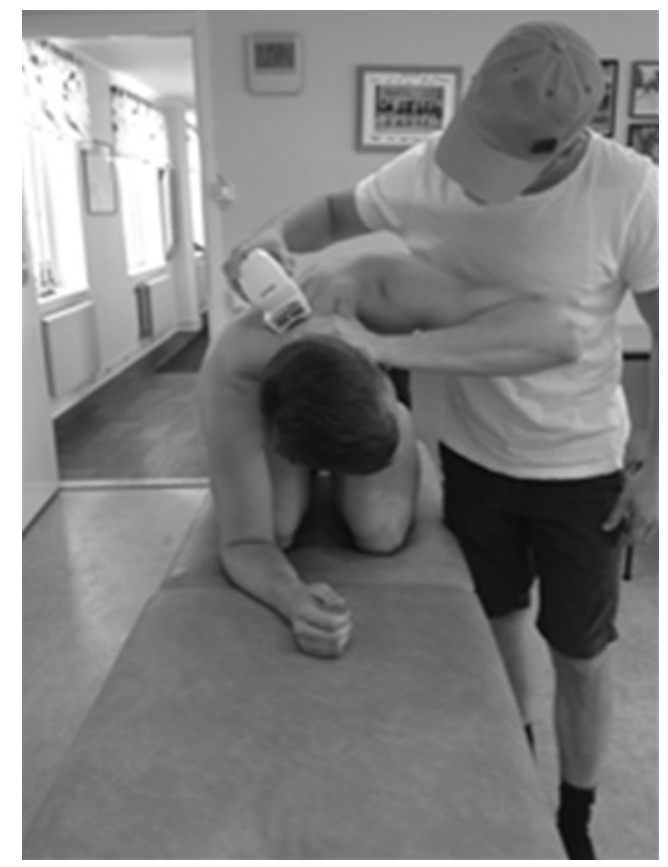

Fig. 3. Measuring the degrees of thoracic rotation using a digital inclinometer.

tral position with fully extended knees. At the end of range of motion in both these movements, the kyphometer was used between the markings at T2-T3 and T11-T12 to obtain the degrees for full flexion and extension of the thoracic spine. Therapist $2 \mathrm{read}$ and wrote down each test result. These test methods and instruments have been used in earlier studies by Alricsson et al. (2003) and Alricsson and Werner (2004, 2006). DeBrunner's kyphometer has an inter-rater reliability of intraclass correlation coefficient (ICC) 0.84-0.98 and an intrarater reliability of ICC 0.92-0.98 (Barret et al., 2014).

\section{Lumbar locked thoracic rotation test}

This test was used to obtain the participants' thoracic rotation ability. The participant was placed in 4-point kneeling position on a bench and instructed to sit back on the heels and place the elbows in front of and in contact with their knees while keeping the forearms straight ahead (Fig. 2). The therapist placed a digital inclinometer towards the spine at T2-T3 level, which indicated the starting position marked as 0 degrees on the inclinometer. The participant was then instructed to place one hand in the arc of his/her neck and slowly rotate the thoracic spine as much as possible without allowing the buttocks to come off the feet or extending the lumbar spine (Fig. 3). The inclinometer was held steady against the spine through the entire movement, and the end range of motion obtained a new value by the inclinometer in- 


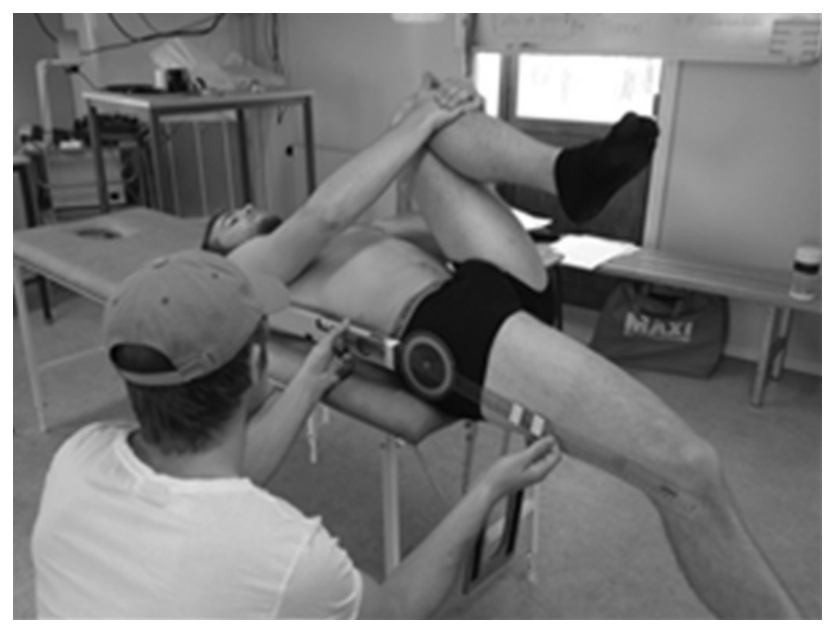

Fig. 4. Thomas test for measuring passive hip extension.

dicating the total rotation of the thoracic spine on that side. The right side was tested first throughout the entire study. This test has an intrarater reliability of ICC 0.90 (Johnson et al., 2012).

\section{Modified Thomas test}

The present test was designed by Kendall et al. (2005) to measure the degree of hip extension. The participant was instructed to lie supine on a bench with the hips and buttocks sticking out over the edge of the table. Both knees of the participant were tucked in towards the chest and held by the participant's arms to keep the pelvis and spine in a backward tilted position, to avoid arching of the back during testing. The hips were then tested one at a time by allowing the participant to carefully extend one of the legs towards the floor while still keeping the other knee tucked in towards the chest using both arms. The degree of extension was measured at the end range of motion without allowing the participant to achieve further extension by muscle force. One of the therapists used a modified goniometer to measure the angle of extension while the other therapist made sure that there was no movement of the spine and pelvis (Fig. 4). The left leg of all the participants was tested first throughout the entire study. This test has an interrater reliability of ICC 0.89-0.92 (Clapis et al., 2008; Dennis et al., 2008) and an intrarater reliability of ICC 0.91-0.93 (Dennis et al., 2008; Winters et al., 2004).

\section{Prone active straight leg raising}

In order to determine the participant's ability to control the pelvis and low back during hip extension, the participant was in prone position on a bench and was instructed to slowly lift one of the legs $20 \mathrm{~cm}$ of the bench while keeping the knee fully extend-

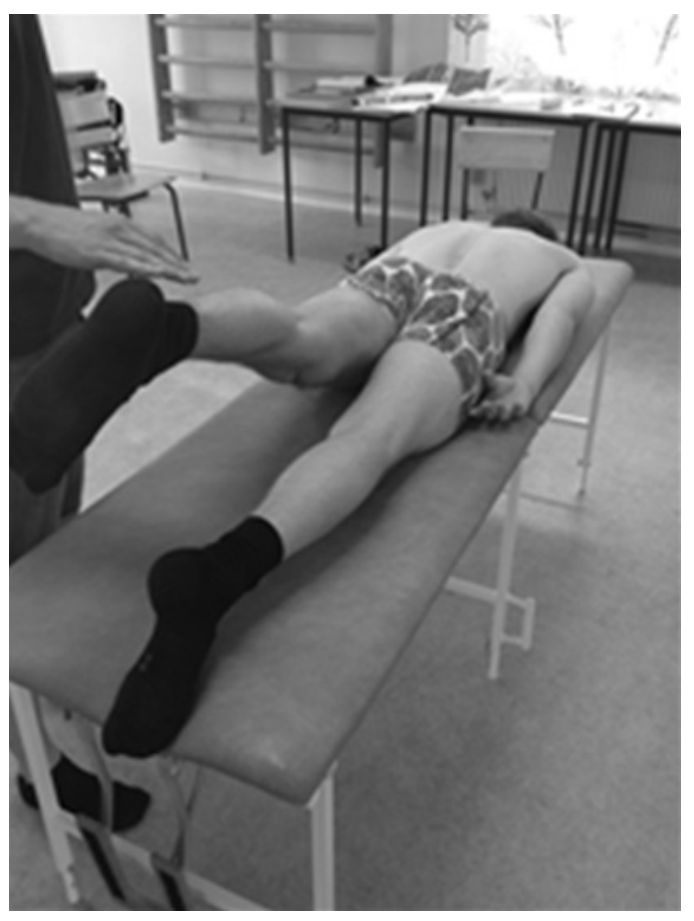

Fig. 5. Prone active straight leg rising for measuring active hip extension.

ed (Fig. 5). The therapists stood at the foot of the bench and observed the participant's pelvis and lumbar spine during the test to look for any deviation of the pelvis and spine, which would indicate inability to control these areas during this movement. The excessive movements were graded as rotation, hyperextension or lateral flexion of the lumbar spine, and both therapists needed to agree in order to consider the test as positive. The present test has $\mathrm{k}$ measure of agreement 0.72 for left leg and 0.76 for right leg (Murphy et al., 2006).

\section{Statistical analysis}

Descriptive statistics (means \pm standard deviations [range]) were used for background data. Pearson correlation coefficient was employed for correlation analysis. Regression analysis was used if a significant correlation was found. Pearson correlation was also used to detect confounders. Chi-square test was used to find a relationship between the prone active straight leg raising (PASLR) test and presence of LBP. The level of significance was set a priori at $\alpha<0.05$ in all statistical tests.

\section{RESULTS}

None of the variables of descriptive information showed any significant correlation with pain score (Table 1). Thoraco-lumbar 
Table 1. Characteristics of the young elite cross-country skiers who participated in this study $(n=51)$

\begin{tabular}{lcc}
\hline Characteristic & Mean \pm SD (range) & $\begin{array}{c}\text { Individual pain score } \\
\text { (P-value) }\end{array}$ \\
\hline Trained seriously since age (yr) & $13.8 \pm 1.9(7-16)$ & $0.1(0.70)$ \\
No. of competitions per season & $16.5 \pm 5.9(3-30)$ & $0.2(0.26)$ \\
Training hours/week preseason & $11.3 \pm 2.6(4-18)$ & $-0.1(0.58)$ \\
Training hours/week season & $9.0 \pm 1.6(5-15)$ & $0.1(0.50)$ \\
Skate per season (\%) & $52.8 \pm 13.4(20-95)$ & $0.0(1.0)$ \\
Classic per season (\%) & $47.3 \pm 13.4(5-80)$ & $0.0(1.0)$ \\
Skate per preseason (\%) & $49.4 \pm 13.1(10-95)$ & $0.0(0.77)$ \\
Classic per preseason (\%) & $50.6 \pm 13.1(5-90)$ & $0.0(0.77)$ \\
Number/week of strength training & $2.2 \pm 0.8(1-5)$ & $0.1(0.32)$ \\
Number/week of stretch training & $1.5 \pm 1.8(0-7)$ & $0.0(0.80)$ \\
\hline
\end{tabular}

SD, standard deviation.

Table 2. Descriptive value in degrees of sagittal alignment, thoracic and lumbar range of motion and Thomas test $(n=51)$

\begin{tabular}{lcc}
\hline Variable & Mean \pm SD (range) & Individual pain score (P-value) \\
\hline Kyphosis & $41.2 \pm 7.7(25-59)$ & $-0.1(0.49)$ \\
Lordosis & $-33.4 \pm 8.6(-54$ to -12$)$ & $-0.9(-0.19)$ \\
Thoraco-lumbar relation & $7.8 \pm 8.5(-12$ to 25$)$ & $-0.3(0.05)^{*}$ \\
Thoracic flexion ability & $17.0 \pm 6.2(6-34)$ & $0.2(0.12)$ \\
Thoracic extension ability & $-17.1 \pm 10.0(-39$ to 8$)$ & $0.1(0.39)$ \\
Thoracic rotation right & $52.2 \pm 10.1(17-71)$ & $0.1(0.42)$ \\
Thoracic rotation left & $47.2 \pm 14.9(4-74)$ & $0.2(0.12)$ \\
Thomas right & $-8.2 \pm 6.6(-33$ to 2$)$ & $-0.2(0.28)$ \\
Thomas left & $-6.8 \pm 7.5(-35$ to 8$)$ & $0.0(0.87)$ \\
\hline
\end{tabular}

*Significant correlation.

$\mathrm{SD}$, standard deviation.

relation has a significant correlation with pain score, and none of the other tests have a significant correlation (Table 2).

The participant's degrees of kyphosis, lordosis, and thoraco-lumbar relation are illustrated on the y-axis (Fig. 6). Participants' pain score is illustrated in same graph on the $\mathrm{x}$-axis. The black lines represent the regression lines of kyphosis, lordosis, and the thoraco-lumbar relation. Our regression model for the thoraco-lumbar relations $(\mathrm{x})$ impact on pain score $(\mathrm{y})$ has the following appearance $y=-0.069 x+2.280$ (standard error of estimate, 0.034). This model gives a significant nexus with significance level $P<0.05$.

The odds ratio for having LBP with a positive PASLR was 1.026 with a $95 \%$ confidence interval (0.337-3.123).

The most bothersome skiing technique for subjects with any LBP was the diagonal technique (35.7\%), while $10.7 \%$ considered both the diagonal and the double pooling technique to be

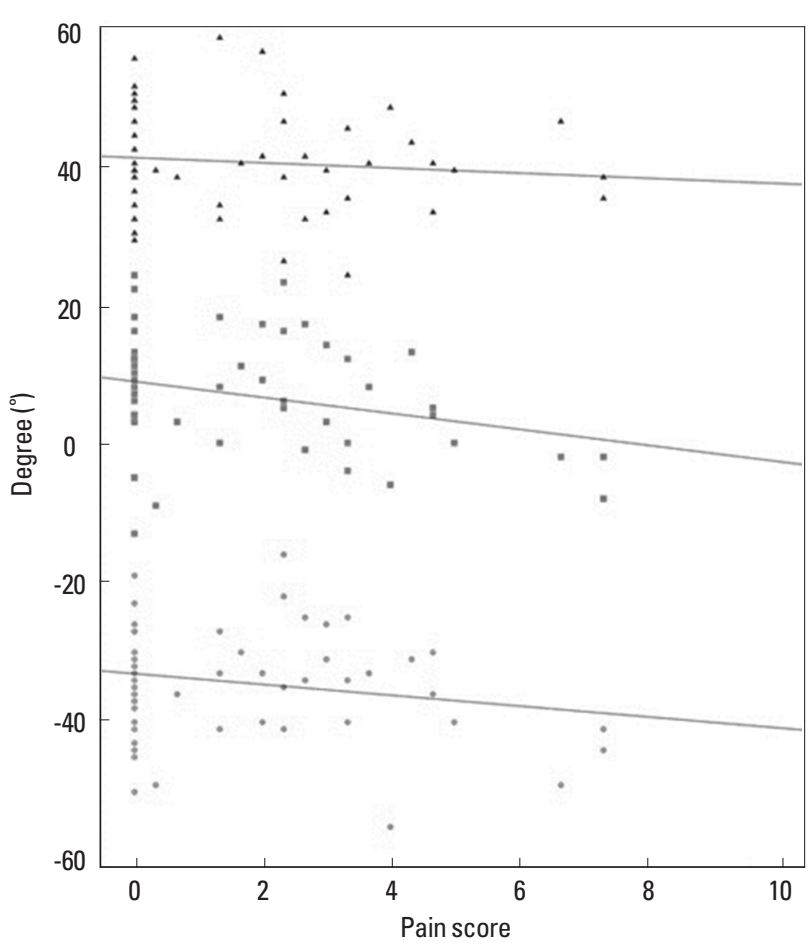

Fig. 6. Scatter plot over sagittal alignment with linear regression lines. Triangles represent kyphosis, squares represent thoraco-lumbar relation and circles represent lordosis.

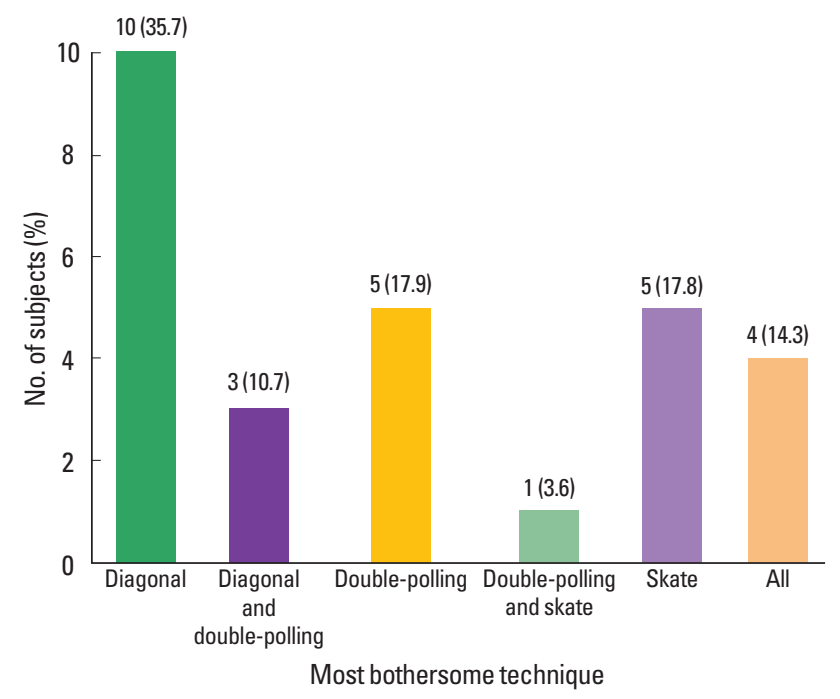

Fig. 7. The most bothersome technique among subjects with low back pain. Percent in staples represent the different techniques of 100\% of total. Values of bars are as presented number of subjects (\%).

equally bothersome. In total, $14.3 \%$ considered all techniques, i.e., both skating and classical skiing, to be bothersome (Fig. 7). 


\section{DISCUSSION}

The purpose of the present study was to investigate any relations between spinal alignment, mobility in the hips and thoracic spine, with LBP in young elite cross-country skiers from a skiing high school in Sweden.

The study showed a significant negative correlation between the thoraco-lumbar relation and pain score. This can be interpreted as an increased sum of degrees between the lumbar lordosis and thoracic kyphosis, resulting in a higher probability of having LBP. It is worth noting that it was only the relationship between the lordosis and the kyphosis that correlated with LBP. The study found no correlation between LBP and degrees of kyphosis or lordosis alone. Mellin (1990) however, found that young girls with LBP had a more pronounced lordosis than subjects without LBP. Because the present study only focused on possible correlations, one cannot draw any conclusions about the cause for these findings. More prospective studies are needed.

The increased lordosis puts higher stress on posterior elements and may leads to excessive tension in the back muscles (Magee, 2008; Ogilvie and Sherman, 1987; Roussouly and Pinheiro-Franco, 2011). Another hypothesis for the correlation between the thoraco-lumbar relation and LBP is a forward displacement of the centre of mass, which would further increase the stress on the posterior elements. A speculation could be that a more pronounced kyphosis may be an adaptation to avoid LBP in this technical skill. A study by Alricsson and Werner (2006) reported an increase in thoracic kyphosis over a 5-yr period among young skiers, and this was also correlated with an increase in LBP. This is in contrast to the present study. The rather small and young population in Alricsson and Werner's (2006) study, compared to the present study is worth mentioning. However, in the present study the correlation was weak, and it is therefore difficult to draw any solid conclusions based on these statistics.

Earlier studies have determined the diagonal technique in classical skiing as being more problematic and provocative for skiers with LBP than other styles like skating and double poling (Alricsson and Werner, 2005; Eriksson et al., 1996; Renstrom and Johnson, 1989). Our study also confirms these findings. One hypothesis for this relation can be that insufficient range of motion in hip extension and thoracic rotation could be provoked by the lumbar spine, and we found no correlation between thoracic mobility and LBP nor between mobility of the hips and LBP. The results of the present study therefore suggest that the range of motion of the hips and the thoracic spine are not the primary cause of the pres- ence of LBP among cross-country skiers. With this in mind, other properties of these joints may very well have an effect on LBP and should always be taken into consideration when it comes to full body movements.

Motor controls of the trunk, pelvis, and hips have been in focus in many research studies about LBP. As motor control is very complex in its nature and very difficult to measure without advanced equipment, a test for movement screening was used in the present study. The purpose of the PASLR test was to determine whether there was any relationship between a visibly detectable altered movement pattern in PASLR and LBP. The test used for this has been proven to have good reliability in a study by Murphy et al. (2006). Excessive movements of the spine during testing were interpreted as an inability to control the pelvis and lower back although this might be a simplified interpretation. As the present study was unable to detect any correlations between PASLR and LBP, the lack of sport-specific nature of the test is a possible scapegoat for the poor result.

The importance of neuromuscular control of the trunk and spine has been thoroughly researched and earned a lot of attention over last few decades in the prevalence and treatment of LBP (Ferreira et al., 2004; Hodges, 2001; Hodges and Richardson, 1999). In concordance with these findings, one common conception among trainers at the ski high school is that there is a difference in technique used to return to upright from a position of full trunk flexion between skiers with and without LBP. With this in mind, Luomajoki et al. (2008) have studied LBP and clinical motor control tests showing that people with chronic LBP had poorer test results. We, therefore, encourage future studies to evaluate and develop sport specific ocular motor control tests for cross-country skiers.

Strengths of this study were our high number of participants and the consistent testing procedure. Many studies in this field of research are fairly old and for the most part conducted before the 21 st century. Worth noticing is that the equipment and technique in cross-country skiing have changed since these studies were done. One example is that double-poling technique has developed from stiff lower limb movements with extreme hip flexion to a more upright position with increased movements in the knees and ankles (Holmberg et al., 2013). Another example is the larger proportion of skating today. The skiing equipment has become lighter and more advanced. As equipment and technique progress, the demands on the athletes will continue to change; therefore, it is of high importance that new research is being done in order to develop the knowledge of intervention and prevention of 
the injuries that occur.

The relation of thoracic kyphosis and lumbar lordosis seems to be correlated with LBP, according to the present study. The reasons for this are still unknown, and more research on the specific biomechanics of the lumbar spine in cross-country skiing might reveal further clues. To understand whether sagittal alignment is the cause of pain or vice versa, this matter will need further prospective research. In accordance with earlier studies, the diagonal technique was reported as the most problematic technique for those with LBP. The LBP among young elite cross-country skiers cannot be correlated to range of motion in the thoracic spine nor in the hips, according to our research.

\section{CONFLICT OF INTEREST}

No potential conflict of interest relevant to this article was reported.

\section{REFERENCES}

Airaksinen O, Brox JI, Cedraschi C, Hildebrandt J, Klaber-Moffett J, Kovacs $\mathrm{F}$, Mannion AF, Reis S, Staal JB, Ursin H, Zanoli G; COST B13 Working Group on Guidelines for Chronic Low Back Pain. Chapter 4. European guidelines for the management of chronic nonspecific low back pain. Eur Spine J 2006;15 Suppl 2:S192-300.

Alricsson M, Harms-Ringdahl K, Eriksson K, Werner S. The effect of dance training on joint mobility, muscle flexibility, speed and agility in young cross-country skiers: a prospective controlled intervention study. Scand J Med Sci Sports 2003;13:237-243.

Alricsson M, Werner S. The effect of pre-season dance training on physical indices and back pain in elite cross-country skiers: a prospective controlled intervention study. Br J Sports Med 2004;38:148-153.

Alricsson M, Werner S. Self-reported health, physical activity and prevalence of complaints in elite cross-country skiers and matched controls. J Sports Med Phys Fitness 2005;45:547-552.

Alricsson M, Werner S. Young elite cross-country skiers and low back pain-A 5-year study. Phys Ther Sport 2006;7:181-184.

Andersson E, Pellegrini B, Sandbakk O, Stüggl T, Holmberg HC. The effects of skiing velocity on mechanical aspects of diagonal cross-country skiing. Sports Biomech 2014;13:267-284.

Bahr R, Andersen SO, Løken S, Fossan B, Hansen T, Holme I. Low back pain among endurance athletes with and without specific back loading--a cross-sectional survey of cross-country skiers, rowers, orienteerers, and nonathletic controls. Spine (Phila Pa 1976) 2004;29:449-454.

Barrett E, McCreesh K, Lewis J. Reliability and validity of non-radio- graphic methods of thoracic kyphosis measurement: a systematic review. Man Ther 2014;19:10-17.

Bergstrøm KA, Brandseth K, Fretheim S, Tvilde K, Ekeland A. Back injuries and pain in adolescents attending a ski high school. Knee Surg Sports Traumatol Arthrosc 2004;12:80-85.

Clapis PA, Davis SM, Davis RO. Reliability of inclinometer and goniometric measurements of hip extension flexibility using the modified Thomas test. Physiother Theory Pract 2008;24:135-141.

Dennis RJ, Finch CF, Elliott BC, Farhart PJ. The reliability of musculoskeletal screening tests used in cricket. Phys Ther Sport 2008;9:25-33.

Eriksson K, Németh G, Eriksson E. Low back pain in elite cross-country skiers. A retrospective epidemiological study. Scand J Med Sci Sports 1996;6:31-35.

Farfan HF, Cossette JW, Robertson GH, Wells RV, Kraus H. The effects of torsion on the lumbar intervertebral joints: the role of torsion in the production of disc degeneration. J Bone Joint Surg Am 1970;52:468497.

Ferreira PH, Ferreira ML, Hodges PW. Changes in recruitment of the abdominal muscles in people with low back pain: ultrasound measurement of muscle activity. Spine (Phila Pa 1976) 2004;29:2560-2566.

Hodges PW. Changes in motor planning of feedforward postural responses of the trunk muscles in low back pain. Exp Brain Res 2001;141:261266.

Hodges PW, Richardson CA. Altered trunk muscle recruitment in people with low back pain with upper limb movement at different speeds. Arch Phys Med Rehabil 1999;80:1005-1012.

Holmberg HC, Lindinger S, Stöggl T, Eitzlmair E, Müller E. Biomechanical analysis of double poling in elite cross-country skiers. Med Sci Sports Exerc 2005;37:807-818.

Holmberg LJ, Lund Ohlsson M, Supej M, Holmberg HC. Skiing efficiency versus performance in double-poling ergometry. Comput Methods Biomech Biomed Engin 2013;16:987-992.

Johnson KD, Kim KM, Yu BK, Saliba SA, Grindstaff TL. Reliability of thoracic spine rotation range-of-motion measurements in healthy adults. J Athl Train 2012;47:52-60.

Kendall FP, McCreary EK, Provance PG, Rodgers MM, Romani WA. Muscles testing and function with posture and pain. 5th ed. Baltimore: Williams and Wilkins; 2005.

Lindinger SJ, Göpfert C, Stöggl T, Müller E, Holmberg HC. Biomechanical pole and leg characteristics during uphill diagonal roller skiing. Sports Biomech 2009;8:318-333.

Luomajoki H, Kool J, de Bruin ED, Airaksinen O. Movement control tests of the low back; evaluation of the difference between patients with low back pain and healthy controls. BMC Musculoskelet Disord 2008;9:170. 
Magee DJ. Orthopedic physical assessment. 5nd ed. St Louis (MO): Saunders Elsevier; 2008.

Mahlamäki S. Back problems among young cross-country skiers. Original Report,15. Kuopio (FI): University of Eastern Finland - Kuopio Campus; 1987.

Mellin G. Correlations of spinal mobility with degree of chronic low back pain after correction for age and anthropometric factors. Spine (Phila Pa 1976) 1987;12:464-468.

Mellin G. Decreased joint and spinal mobility associated with low back pain in young adults. J Spinal Disord 1990;3:238-243.

Murphy DR, Byfield D, McCarthy P, Humphreys K, Gregory AA, Rochon R. Interexaminer reliability of the hip extension test for suspected impaired motor control of the lumbar spine. J Manipulative Physiol Ther 2006;29:374-377.

Ogilvie JW, Sherman J. Spondylolysis in Scheuermann's disease. Spine (Phila Pa 1976) 1987;12:251-253.
Renstrom P, Johnson RJ. Cross-country skiing injuries and biomechanics. Sports Med 1989;8:346-370.

Ristolainen L, Heinonen A, Turunen H, Mannström H, Waller B, Kettunen JA, Kujala UM. Type of sport is related to injury profile: a study on cross country skiers, swimmers, long-distance runners and soccer players. A retrospective 12-month study. Scand J Med Sci Sports 2010;20:384-393.

Roussouly P, Pinheiro-Franco JL. Biomechanical analysis of the spino-pelvic organization and adaptation in pathology. Eur Spine J 2011;20 Suppl 5:609-618.

Von Korff M, Ormel J, Keefe FJ, Dworkin SF. Grading the severity of chronic pain. Pain 1992;50:133-149.

Winters MV, Blake CG, Trost JS, Marcello-Brinker TB, Lowe LM, Garber MB, Wainner RS. Passive versus active stretching of hip flexor muscles in subjects with limited hip extension: a randomized clinical trial. Phys Ther 2004;84:800-807. 